\title{
The Production of Cold-rolled Steel Sheet of Extra-deep Drawing Quality by Continuous Annealing Process*
}

\author{
By Nobuo FUKUDA** and Mineo SHIMIZU **** $^{* *}$
}

\begin{abstract}
Synopsis
Ti-stabilized very low $\mathrm{C}$ steel has a uniform distribution of very fine precipitates ( $\mathrm{TiC}$ ) already formed in the hot-rolled state. These precipitates existing prior to cold rolling are effective in developing a strong $\{111\}$ recrystallization texture upon annealing after cold rolling. Thus, the slow heating up to an annealing temperature such as carried out for Al-killed steel to obtain effective precipitates or pre-precipitation clusters is not necessary for Ti-stabilized steel. Lowering $\mathrm{C}$ content of the steel to $0.01 \%$ or less results in great increase of the grain size and the $\bar{r}$ value in a very short time with a rize of annealing temperature. Ti-stabilized very low $\mathrm{C}$ steel (e.g., $0.005 \% \mathrm{C}-0.1 \% \mathrm{Ti}$ ) therefore can afford a very high $\bar{r}$ value of above 2.0 even under application of a rapid annealing cycle with heating rates from $10^{4}$ to $10^{5} \mathrm{C} / \mathrm{sec}$ and with soaking times of a ferw mimutes.

Quench-aging does not occur at all in Ti-stabilized steel rapidly cooled from the annealing temperature since the $\mathrm{C}$ (and $\mathrm{N}$ ) in the steel is stabilized by $\mathrm{Ti}$. Therefore, continuously annealed Ti-stabilized steel is non-aging and very soft without the application of overaging treatment.

Ti-stabilized very low $\mathrm{C}$ steels are most suitable for producing non-aging steel sheets having extra-deep drawing quality by continuous annealing process.
\end{abstract}

\section{Introduction}

For the production of cold-rolled steel sheets of extra-deep drawing quality the box or pack annealing method (batch type) has been used so far; any continuous annealing method (a short annealing cycle of quick heating and rapid cooling) has not been employed. This has been mainly for the following reasons. If the heating rate for annealing is increased to an extent at which the time available is not sufficient for obtaining very fine precipitates (or pre-precipitation clusters) in size and distribution conducting to the development of $\{111\}$ recrystallization texture which is desirable for the drawing quality of sheets, the $r$ value, for example, of Al-killed steel is considerably deteriorated with such rise in the heating rate. ${ }^{1,2}$ Also, the holding time at an annealing temperature is too short for sufficient crystal growth, producing a fine grain structure with a high yield point and low elongation. The preferential growth of $\{111\}$ grains by encroaching on the grains of other orientations cannot generally be expected, and any improvement of $r$ value due to the selective grain growth effect, therefore, will not be produced. Moreover, supersaturated $\mathrm{C}$ in solid solution due to rapid cooling from an annealing temperature causes so-called quench age-hardening of steel, to which strain agehardening is also added if the strip is skin-passed at the final processing stage, thus further deteriorating the mechanical properties of steel.
In his report on the continuous annealing of deep drawing quality steel, Blickwede ${ }^{3)}$ showed that Alkilled steel, when rapidly heated, recrystallizes into very fine crystal grain within a short time of $10 \mathrm{sec}$ and has virtually no growth of grain even if soaked for $20 \mathrm{hr}$. For reducing the solid solution C amount generated by rapid cooling, overaging, i.e., heating to an appropriate temperature after or in the course of cooling from an annealing temperature is effective. But according to the test result by Blickwede the steel softens to a greater degree if overaged at a comparatively lower temperature (the required overaging time, however, will be prolonged). Garber ${ }^{4}$ suggested a new cycle for continuous annealing of tin plates consisting of quenching from an annealing temperature $\left(700^{\circ} \mathrm{C}\right)$ to approximately $300^{\circ} \mathrm{C}$ and coiling the strip at this temperature. Self-aging, namely, overaging of the strip by the heat it holds will occur, he reported, softening the strip steel.

As described above, three problems are yet to be solved for production of continuously annealed coldrolled steel sheets of deep drawing quality. First, the growth of crystal grain in a short time after recrystallization can be promoted by minimizing the precipitates which prevent grain growth. In order to minimize such precipitates, a method of controlling chemical compositions of steel or heat hysteresis should be worked out, or, as an alternative, raising the annealing temperature can be effective. Secondly, to prevent the increase of solid solution $\mathrm{C}$ amount due to rapid cooling, precipitation of $\mathrm{C}$ as carbide by application of an overaging process may suffice, and prior addition of an appropriate carbide forming element to steel will also be effective. The last and greatest problem which hinders the application of a continuous annealing cycle to the production of cold-rolled steel sheets of extra-deep drawing quality of high $r$ value is the general difficulty in obtaining preferential nucleation of $\{111\}$ recrystallized grain and its growth when the steel is rapidly heated.

The directionality of recovery or nucleation and growth of recrystallized grain has been ascertained experimentally by many; very fine precipitates (or pre-precipitation clusters) precipitating prior to recovery or recrystallization reduce the frequency of nucleation for recrystallization, and though they are not too much restrictive of generation of $\{111\}$ grains which readily recrystallize, they further restrain the

* Originally published in Tetsu-to-Hagané, 61 (1975), 817, in Japanese. English version received July 19 , 1976.

** Sakai Works, Nippon Steel Corp., Chikko-Yahata-machi, Sakai 590.

*** Formerly, Process Technology R \& D Laboratories, Nippon Steel Corp. Now, Department of Metallurgy, Faculty of Engineering, Kyushu University, Hakozaki-cho, Fukuoka 812. 
generation of $\{100\}$ grains which do not readily recrystallize, thus promoting the predominant development of $\{111\}$ recrystallization texture.

The present authors had thought that these effective precipitates should not necessarily be precipitated during the heating process for annealing, but the same role could be played by them even when they were precipitated in hot-rolled sheet prior to cold rolling. As the authors reported previously, $\left.{ }^{5}\right)$ it could be expected that positive development of $\{111\}$ recrystallization texture with Ti-bearing steel is possible even if it having $\mathrm{TiC}$ precipitates already in the hot-rolled stage followed by cold rolling and rapidly heated annealing. It could also be expected, however, that the precipitates formed during annealing and those before cold rolling, though both of them positively develop $\{111\}$ in annealed sheets, may act differently on the mechanism of recrystallization texture formation.

Another possibility in relation to the mechanism of texture formation of Ti-bearing steel was reported by Takahashi, et al.6,7) They pointed out that the microscopic difference in cold rolling textures between Ti-stabilized steel and other steel (e.g., Al-killed steel) was responsible to the development of recrystallization textures upon rapid annealing.

$\mathrm{C}$ and $\mathrm{N}$ of hot-rolled Ti-stabilized steel strip are almost stabilized as shown by the result of internal friction measurement, ${ }^{5)}$ and therefore it could be anticipated that no overaging treatment would be necessary to prevent quench-aging of the strip quenched after annealing for the reason that the stabilized $\mathrm{C}$ and $\mathrm{N}$ would not decompose by annealing after cold rolling. Thus, it was indicated that the problems due to quick heating and rapid cooling could be solved by the use of Ti-stabilized steel and therefore that this would be the most appropriate steel for the production of cold-rolled steel sheets of extra-deep drawing quality through continuous annealing process.

\section{Method of Experiment}

In order to study the correlation between heating rate for annealing and the $r$ value, samples were taken from the production line of $0.8 \mathrm{~mm}$ thick cold-rolled steel sheets of Ti-stabilized very low $\mathrm{C}$ steel shown in Table 1. The specifications for these sheets were a finish hot rolling temperature of $930^{\circ} \mathrm{C}$, coiling temperature of $550^{\circ} \mathrm{C}$, finish hot rolling thickness of $2.7 \mathrm{~mm}$, and cold reduction of $70 \%$. The required number of rectangular specimens of $45 \mathrm{~mm}$ width and $400 \mathrm{~mm}$ length were sheared off from the coldrolled sheets. The annealing furnace used was such that electricity was directly fed through the specimens to heat them and the heating rate was changed in steps of $500^{\circ}, 700^{\circ}, 900^{\circ}$, and $1100^{\circ} \mathrm{C} / \mathrm{min}$ by controlling the current. In addition, a salt bath was used to accelerate the heating rate to $1900^{\circ} \mathrm{C} / \mathrm{min}$. Annealing was conducted at $800^{\circ} \mathrm{C}$ for $5 \mathrm{~min}$. Then power was cut off and the furnace door was opened to allow air-cooling of the specimens. JIS No. 5 tension test-pieces were obtained from the annealed specimens to measure the $r$ value. Axial densities by means of inverse pole figures were measured, and also $\{200\}$ pole figures were prepared.

Then the correlations between crystal grain size and the $r$ value were investigated, on the basis of the results obtained by a laboratory study carried out on the annealing conditions to improve the $r$ value by promoting the growth of crystal grain. Samples of $0.8 \mathrm{~mm}$ cold-rolled steel sheets (cold reduction of $70 \%$ ) of 4 types of steel, whose chemical compositions are shown in Table 2, were obtained from the production line and subjected to annealing treatments at temperatures varying from $700^{\circ}$ to $900^{\circ} \mathrm{C}$ (holding time $5 \mathrm{hr}$ constant) to produce crystal grains of different sizes. Then the grain size and the $r$ value were measured. For Ti-stabilized very low $\mathrm{C}$ steel included in the 4 types of steel above, annealing conditions required to provide it with the most desirable mechanical properties were studied, namely, by changing the annealing temperature from $900^{\circ}$ to $950^{\circ} \mathrm{C}$ with the holding time at each temperature varying as 1,5 , and $10 \mathrm{~min}$. After air cooling the $r$ value and grain size were measured. A field test was also conducted with the view of establishing the applicability of the laboratory test results thus obtained to the production line. For this test an existing continuous annealing line in the Si-steel works was used. The chemical composition of the sample and the mill practice are shown in Table 3. In the test the holding time was changed by controlling the line strip threading speed. For annealing conditions, a holding time of $1 \mathrm{~min}$ at $900^{\circ} \mathrm{C}$, and a holding time of $4 \mathrm{~min}$ at $850^{\circ}, 900^{\circ}$, and $930^{\circ} \mathrm{C}$ were aimed. Different coils from the same heat were annealed through a box annealing process (both open-coil and tight-coil types) and their properties were compared with those of the continuously an-

Table 1. Chemical composition of Ti-stabilized steel for study on heating rate in short time annealing (wt\%)

\begin{tabular}{c|c|c|c|c|c|c}
$\mathrm{C}$ & $\mathrm{Mn}$ & $\mathrm{Si}$ & $\mathrm{P}$ & $\mathrm{S}$ & $\mathrm{Cu}$ & $\mathrm{O}$ \\
\hline 0.005 & 0.10 & 0.059 & 0.009 & 0.013 & 0.064 & 0.003 \\
Sol. $\mathrm{N}$ & Insol. $\mathrm{N}$ & Sol. Ti & Insol. Ti & Sol. Al \\
\hline 0.0019 & 0.0046 & 0.088 & 0.036 & 0.043
\end{tabular}

Table 2. Chemical composition of steels for study on the relationship between grain size and $r$ value (wt $\%$ )

\begin{tabular}{l|c|c|c|c|c|c|c|c|c}
\multicolumn{1}{c|}{ Steel } & $\mathrm{C}$ & $\mathrm{Si}$ & $\mathrm{Mn}$ & $\mathrm{P}$ & $\mathrm{S}$ & $\mathrm{Cu}$ & $\mathrm{N}$ & Others \\
\hline Rimmed & 0.039 & 0.011 & 0.32 & 0.010 & 0.015 & 0.064 & 0.0020 & \\
V-rimmed & 0.045 & 0.012 & 0.32 & 0.011 & 0.025 & 0.084 & 0.0026 & $0.025 \mathrm{~V}$ \\
Al-killed & 0.049 & 0.012 & 0.33 & 0.011 & 0.016 & 0.066 & 0.0046 & $0.068 \mathrm{Al}$ \\
Ti-stab'd & 0.006 & 0.041 & 0.06 & 0.012 & 0.015 & 0.02 & 0.0042 & $0.096 \mathrm{Ti}$ \\
\hline
\end{tabular}


nealed coils.

Lastly, quench-aging characteristics were investigated. Samples of $0.8 \mathrm{~mm}$ thick cold-rolled Ti-stabilized steel, Al-killed steel and rimmed steel sheets, the chemical compositions of which are shown in Table 4, were taken from the production line. The samples of Al-killed and rimmed steels were annealed at $800^{\circ} \mathrm{C}$ for $1 \mathrm{~min}$ in a laboratory electric heating furnace, then the samples were cooled at the rate of approximately $35^{\circ} \mathrm{C} / \mathrm{sec}$ to $400^{\circ} \mathrm{C}$, at which temperature they were overaged for 0 to $10 \mathrm{~min}$. The electric current control to work out these heat cycles was established by preliminary experimentation. After overaging the samples, the electric current was cut off for air cooling. These annealed samples were subjected to $1 \%$ skin-passing by a laboratory rolling mill, and then to a tension test and an aging test.

\section{Results of Experiment and Discussions}

\section{Heating Rate for Annealing and the $r$ Value}

As is clear from Fig. 1, the dependence of the $r$ value of Ti-stabilized steel on the annealing heating rate was extremely small as expected, and slightly deteriorated when a very fast heating such as salt bath treatment was applied. Notwithstanding this, the absolute value of $\bar{r}$ was high, indicating approximately 2.0. The $r$ value corresponded well with the tendency shown by the changes in the axial density of inverse pole figure in the same figure. The decrease in the $r$ value due to the salt bath treatment was, as expected,
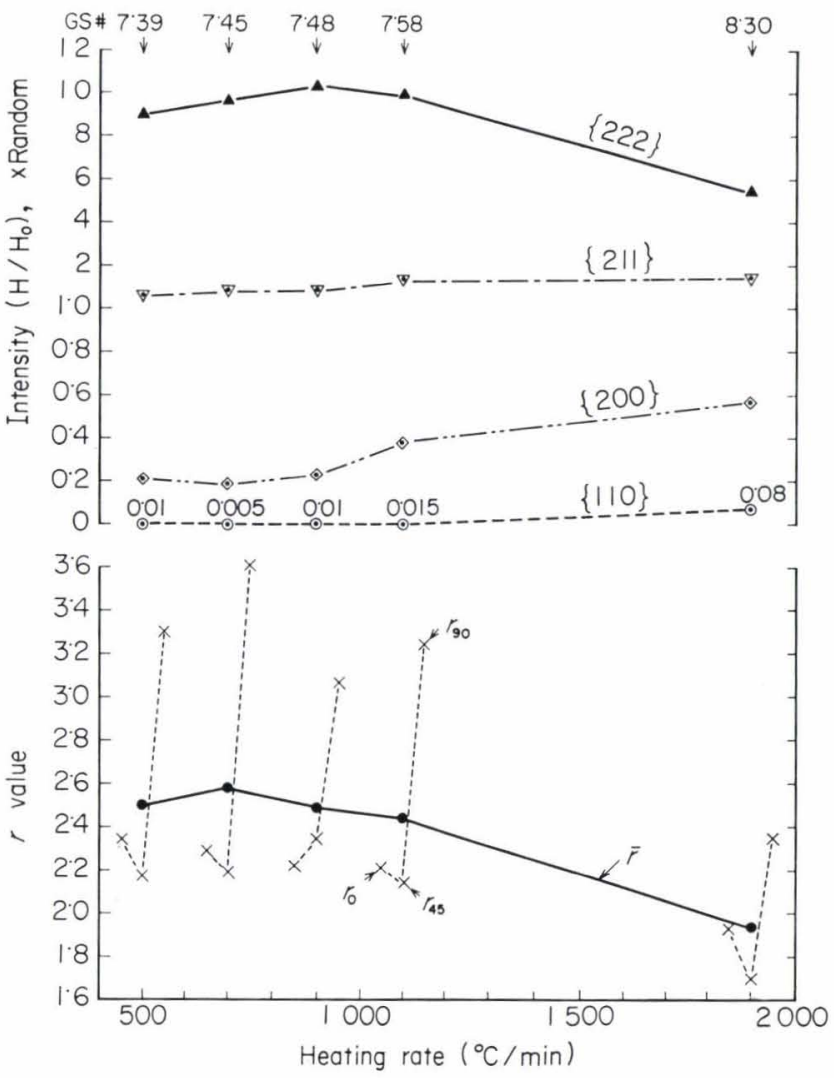

Fig. 1. Effect of heating rate up to annealing temperature on the $r$ value and textures of $\mathrm{Ti}$-stabilized steel cold-rolled $70 \%$ and annealed at $800^{\circ} \mathrm{C}$ for $5 \mathrm{~min}$

Table 3. Sample of Ti-stabilized very low C steel used in production test of continuous annealing

(a) Chemical composition*

\begin{tabular}{cccccccccc} 
C & $\mathrm{Si}$ & $\mathrm{Mn}$ & $\mathrm{P}$ & $\mathrm{S}$ & $\mathrm{Cu}$ & $\mathrm{N}$ & $\mathrm{O}$ & Sol. Ti & Insol. Ti \\
\hline 0.004 & 0.02 & 0.017 & 0.017 & 0.017 & 0.0053 & 0.0061 & 0.005 & 0.065 & 0.037
\end{tabular}

* Check analysis by slab sample (\%)

(b) Mill practice

$\begin{gathered}\text { Slab } \\ 110 \times 935 \mathrm{~mm}\end{gathered} \rightarrow \begin{gathered}\text { Hot rolling } \\ 2.7 \times 935 \mathrm{~mm}\end{gathered} \rightarrow \begin{gathered}\text { Pickling } \\ 2.7 \times 935 \mathrm{~mm}\end{gathered} \rightarrow \begin{gathered}\text { Cold rolling } \\ 0.8 \times 921 \mathrm{~mm}\end{gathered} \mid \rightarrow \begin{gathered}\text { Electrolytic } \\ \text { Cleaning }\end{gathered} \rightarrow \begin{gathered}\text { Continuous } \\ \text { annealing }\end{gathered}$

\begin{tabular}{|c|c|c|c|c|c|}
\hline Coil No. & $30-610-1$ & $30-610-2$ & $30-610-3$ & $30-610-4$ & $30-610-5$ \\
\hline Finish temp. $\left({ }^{\circ} \mathrm{C}\right)$ & & 895 & & & \\
\hline Coil temp. $\left({ }^{\circ} \mathrm{C}\right)$ & & 550 & & & \\
\hline Cold red. (\%) & \multicolumn{5}{|c|}{$70(2.7 \rightarrow 0.8 \mathrm{~mm})$} \\
\hline Anneal temp. $\left({ }^{\circ} \mathrm{C}\right)$ & 900 & 930 & 900 & 850 & 930 \\
\hline Line speed $(\mathrm{m} / \mathrm{min})$ & 8.4 & 9.1 & 31.0 & 9.7 & 31.5 \\
\hline Skin-pass red. (\%) & 0.75 & 0.8 & 0.7 & 0.7 & 0.8 \\
\hline
\end{tabular}

Table 4. Chemical composition of steels for study on overaging effect in short time annealing with rapid cooling (wt\%)

\begin{tabular}{c|cccccccc} 
Steel & C & Si & Mn & P & S & Cu & O & Others \\
\cline { 1 - 7 } Rimmed & $0.09^{*}$ & $0.01^{*}$ & $0.30^{*}$ & N.D. & $0.019^{*}$ & N.D. & N.D. & N.D. \\
\hline Al-killed & 0.042 & N.D. & 0.20 & N.D. & 0.016 & N.D. & 0.007 & 0.0023 \\
\hline Ti-stab'd & 0.008 & 0.02 & 0.10 & 0.009 & 0.010 & 0.03 & 0.002 & N.D. \\
\hline
\end{tabular}

* Ladle analysis, N.D.: Not determined 
attributable to decrease in $\{222\}$ and increase in $\{200\}$. The main orientation of each of the samples, as seen in the pole figures of Fig. 2, consists of $\{554\}\langle 225\rangle \sim$ $\{322\}\langle 269\rangle$ and $\langle 111\rangle / / \mathrm{ND}$. At a heating rate of $1100^{\circ} \mathrm{C} / \mathrm{min}$ or $1900^{\circ} \mathrm{C} / \mathrm{min}$ the $\{100\} / / \mathrm{ND}$ orienta-
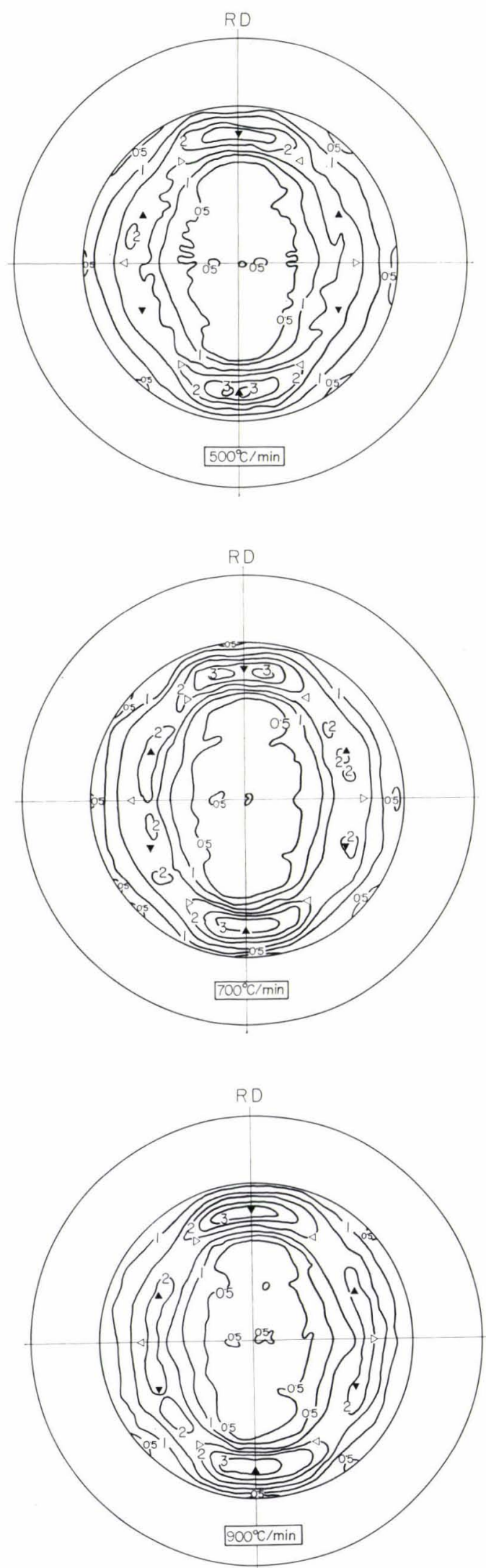

tion increased, endorsing the correctness of the axial density results in Fig. 1.

According to Bennewitz ${ }^{8)}$ the cold-rolled texture of iron and ferrous alloys of the b.c.c. structure consists of rotating system around $\langle 110\rangle$ axis parallel to the rolling direction, i.e., $\quad(111)[\overline{1} 10] \rightarrow(112)[\overline{1} 10] \rightarrow(001)$ $[\overline{1} 10] \rightarrow(211)[01 \overline{1}] \rightarrow(\overline{1} \overline{1} 1)[\overline{1} 10]$, and a rotating system around $\langle 110\rangle$ axis located at $60^{\circ}$ to the rolling direction and at $30^{\circ}$ from the line perpendicular to the rolling plane, i.e., $(112)[\overline{1} 10] \rightarrow(545)[\overline{2} 5 \overline{2}] \rightarrow$ (211)[011]. The main components of the cold-rolled texture are $\{112\}\langle 110\rangle,\{001\}\langle 110\rangle,\{111\}\langle 110\rangle$, and $\{111\}\langle 112\rangle$. When a cold-rolled sheet is annealed, the recrystallized grain of $\{554\}\langle 225\rangle$ orientation holds a rotating relationship of $35^{\circ}$ about common $\langle 110\rangle$ axis of $\mathrm{RD} 60^{\circ}$ and ND30 ${ }^{\circ}$ with the cold-rolled grain of $\{112\}\langle 110\rangle$ orientation as the basis; ${ }^{9)}$ the recrystallized grain of $\{111\}\langle 110\rangle$ orientation holds a rotating relationship of $30^{\circ}$ about the $\mathrm{ND} / /\langle 111\rangle$ axis
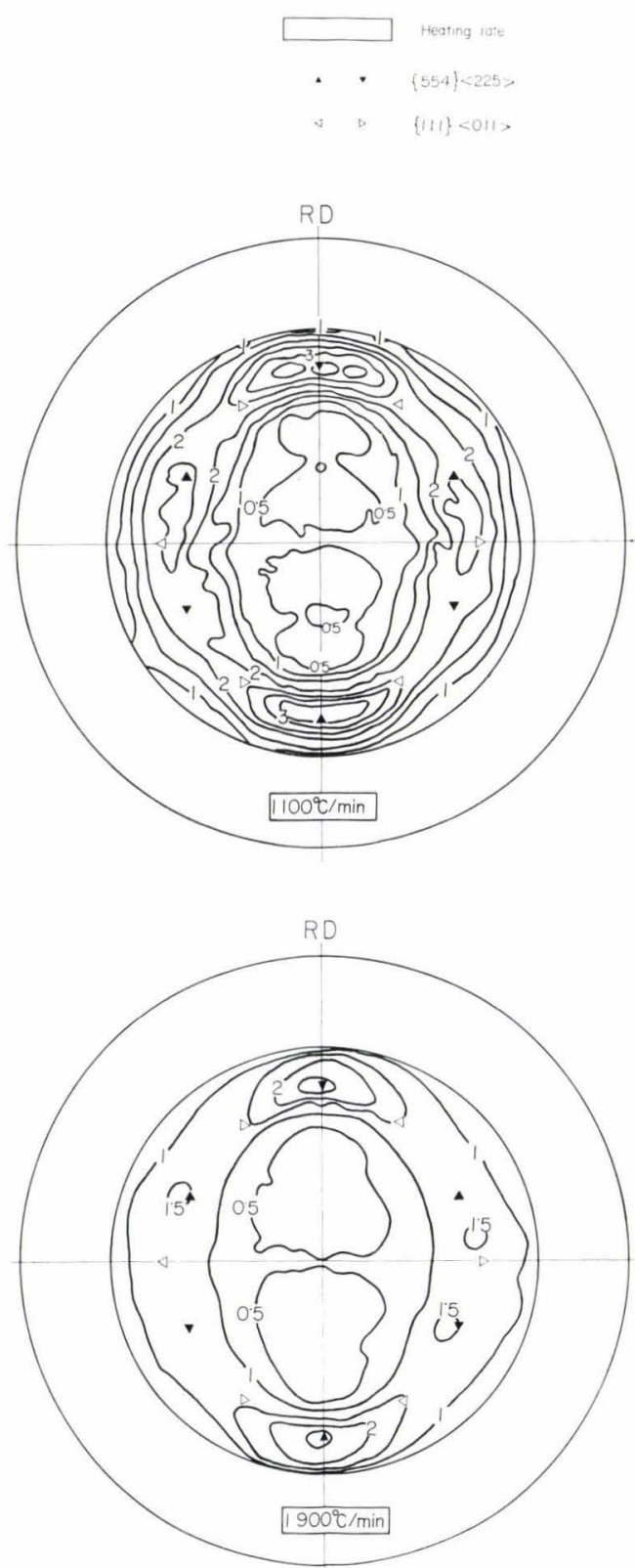

Fig. 2. Change in $\{200\}$-pole figures with heating rates in short time annealing ( $800^{\circ} \mathrm{C}$ for $\left.5 \mathrm{~min}\right)$ of Ti-stabilized steel 
with cold-rolled grain of $\{111\}<112\rangle$ orientation as the basis, or $\{111\}\langle 110\rangle$ grain recrystallizes in situ without any change in orientation. ${ }^{10,11)}$ The stable component $\{100\}<011\rangle$ grain in cold-rolled sheet also recrystallizes in situ, it is considered, since the stored energy due to cold rolling is small. ${ }^{12,13)}$ Therefore, $\{111\}$ or $\{112\}$ which holds high cold-rolled stored energy recrystallizes predominantly, but recrystallization of $\{100\}$ is suppressed because of such small stored energy. If very fine precipitates or pre-precipitation clusters exist in an appropriate size and distribution just prior to recrystallization, such directionality of recrystallization texture formation will be further strengthened and the nucleation of $\{100\}$ grain will thereby be strongly restrained. If, however, the heating rate for annealing becomes extremely high, release of strain of $\{100\}$ grain itself is promoted by the large amount of thermal energy applied in a very short period of time, thus leading to an increase of recrystallized $\{100\}$ grain. In other words, in addition to decrease in the amount of effective precipitates due to rapid heating the effect of the rate of input thermal energy on the frequency of nucleation for recrystallization appears in the process of recovery and recrystallization. Hence, even in the case of Ti-stabilized steel, if the annealing heating rate is increased beyond a certain critical limit, the favorable effect of precipitates on the orientation dependence of stored energy lease (recovery) and recrystallization weaken, thus reducing $\{111\}$ and increasing $\{100\}$, and resulting in an inevitable lowering of the $r$ value to some degree.

Although it was found that a high $r$ value can be obtained even with the adoption of rapid heating for annealing if Ti-stabilized steel having very fine precipitates ( $\mathrm{TiC}$ ) already in the as-hot-rolled sheets is used, these precipitates existing prior to cold rolling cannot be categorically said to play the same part as that of the precipitates (AIN) which precipitate during heating (before recrystallization) on annealing $\mathrm{Al}$ killed steel. Apart from the actual mechanism of the whole process, precipitates of an appropriate size existing in steel before cold rolling have now been proved effective in obtaining a higher $r$ value even with the adoption of rapid heating for annealing.

Furubayashi, et al. ${ }^{14)}$ reported that when hot-rolled sheets of Al-killed low C steel were given a pre-strain of approximately 5 to $10 \%$ and heated to around $500^{\circ} \mathrm{C}$ to promote the precipitation of $\mathrm{AlN},\{111\}$ texture was developed in the steel even after the steel sheets were subjected to rapid heating subsequent to cold rolling. The authors also obtained the $r$ values shown in Fig. 3, after rapid heating and short-time holding for annealing $\left(800^{\circ} \mathrm{C}\right.$ for $\left.1 \mathrm{~min}\right)$ of cold-rolled Al-killed steel strip which had been coiled at varying temperatures subsequent to hot rolling (i.e., change in the state of AlN precipitation). The authors' finding shows that, while in the case of ordinary box annealing the Al-killed steel should be coiled at as low a temperature as possible to retain $\mathrm{Al}$ and $\mathrm{N}$ in supersaturated solid solution prior to cold rolling and should be heated at small rates for annealing to get very fine AIN precipitates or pre-precipitation clusters before recrystallization, in the case of the application of a rapid annealing cycle a high $r$ value will be obtained if the strip is coiled at a high temperature. According to Fig. 3, the $\bar{r}$ value is the maximum when the strip is coiled at $700^{\circ} \mathrm{C}$. Coiled at $750^{\circ} \mathrm{C}$, however, some strips showed a markedly low $\bar{r}$ value. This can be explained by the assumption that coiling of a strip at an excessively high temperature may, in connection with the amount of $\mathrm{Al}$ content, produce precipitates of large sizes, thus losing the effect of very fine precipitates available to rapid annealing. Also, Toda, et al. ${ }^{15)}$ reported that, when a low $\mathrm{C}$ steel with properly controlled amounts of $\mathrm{Mn}, \mathrm{S}$, and $\mathrm{O}$ was coiled at a high temperature of $680^{\circ} \mathrm{C}$ or over to get $\mathrm{MnS}$ to precipitate, $\{111\}$ orientation could be developed by rapid continuous annealing.

Although elueidation of the roles played in texture formation by both types of precipitates, i.e., the precipitates in hot-rolled sheet prior to cold rolling and the precipitates during heating for annealing after cold rolling, must await further study on their mechanisms, it is particularly effective in developing $\{111\}$ by means of rapid heating cycle such as of continuous annealing process so as to obtain a high $r$ value that precipitates of an appropriate size and distribution are already formed in steel prior to cold rolling. Presently, study is being conducted to clarify quantitatively the relationships between the state of the distribution of these precipitates and recrystallization texture.

The authors ${ }^{5}$ measured internal friction of Tistabilized hot-rolled steel sheets and observed precipitates, and reported that $\mathrm{C}$ and $\mathrm{N}$ were almost completely stabilized by $\mathrm{Ti}$ and that very fine precipitates were uniformly distributed in grains. The precipitates observed in a $0.005 \% \mathrm{C}-0.096 \% \mathrm{Ti}$ steel coiled at $750^{\circ}$ and $600^{\circ} \mathrm{C}$ after hot-rolling are shown in Photo. $\mathrm{l}(\mathrm{a})$ and (b), respectively. A precipitate having a diameter of approximately $200 \AA$ was identified as TiC as shown in Photo. 1 (c) through the electron diffraction pattern of an extraction replica. No

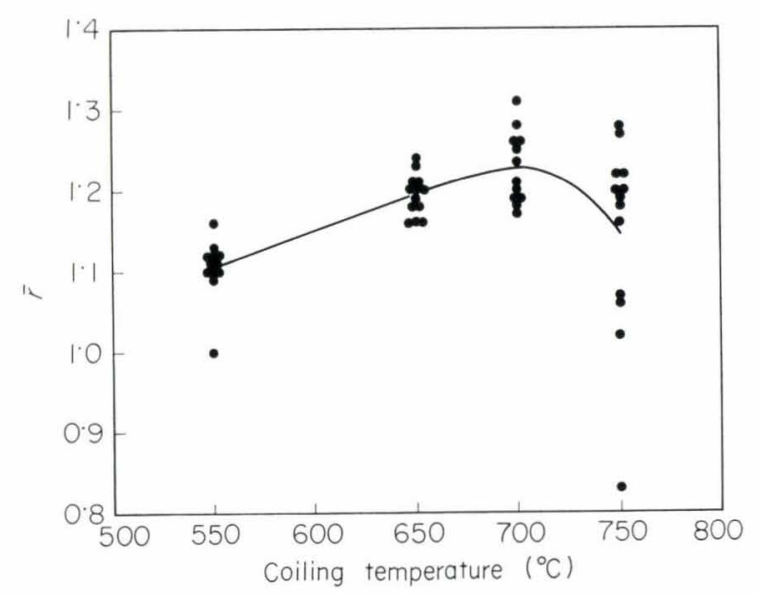

Fig. 3. Effect of coiling temperature on the $r$ value of $(0.035$ $\sim 0.062) \% \mathrm{C}-(0.035 \sim 0.050) \%$ soluble-Al steels, finished at $890^{\circ} \mathrm{C}$, coiled at temperatures, cold-rolled $(65 \sim 72) \%$, and annealed at $800^{\circ} \mathrm{C}$ for $1 \mathrm{~min}$ by rapid cycle 

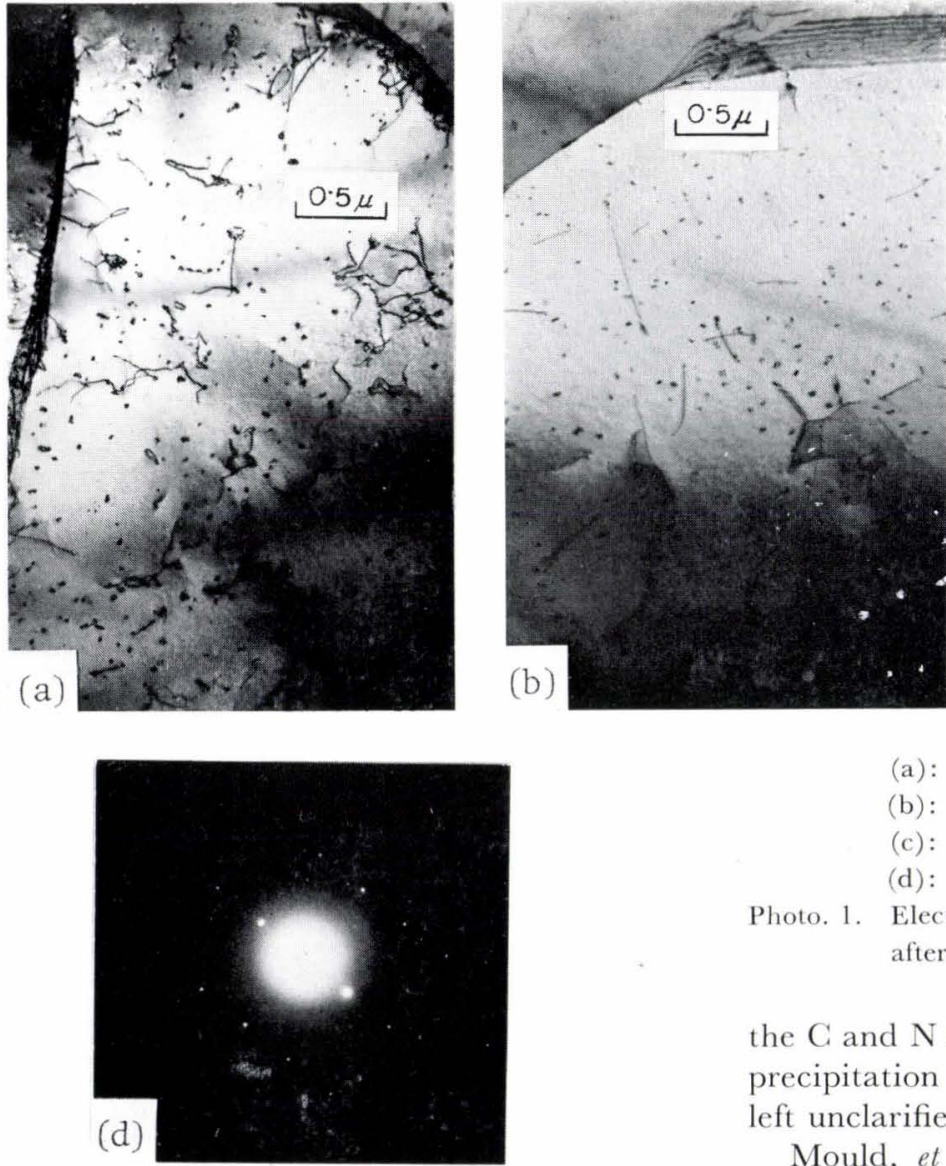

$\overline{1} \overline{1}$

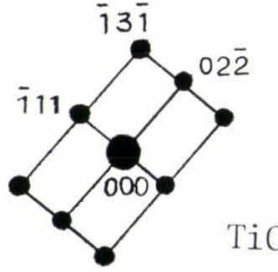

change was observed in the state of precipitation even when the coiling temperature was altered.

The authors also reported ${ }^{5,16)}$ the results of study on the relationships between the size of precipitates in a hot-rolled sheet and the texture of a cold-rolled annealed sheet or its $r$ value, using various low C steels containing different addition elements. The report stated that $\mathrm{V}$-containing steel $(0.07 \% \mathrm{C}-0.04 \% \mathrm{~V}), \mathrm{B}-$ containing steel $(0.038 \% \mathrm{C}-0.0092 \% \mathrm{~B}), \mathrm{P}$ and $\mathrm{Ti}-$ containing steel $(0.007 \% \mathrm{C}-0.240 \% \mathrm{P}-0.115 \% \mathrm{Ti})$, etc., showed precipitates of several thousand $\AA$ especially in the grain boundary in hot-rolled sheets and that no development of $\{111\}$ was observed in the cold-rolled annealed sheets of these steels with their $r$ value kept low (nearly unity).

Kokubo, et al. ${ }^{20)}$ investigated the recrystallization texture of a low $\mathrm{C}$ steel to which a carbide-forming element was added and reported that, when the hotrolled sheet, for example, of a Ta-containing steel was treated for precipitation, the $r$ value of the cold-rolled annealed sheet was improved. The precipitates, in this case, were $\mathrm{TaC}$ with a particle size of 200 to $500 \AA$. Kokubo, et al., however, concluded that the improvement in the $r$ value was attributable to the fact that all

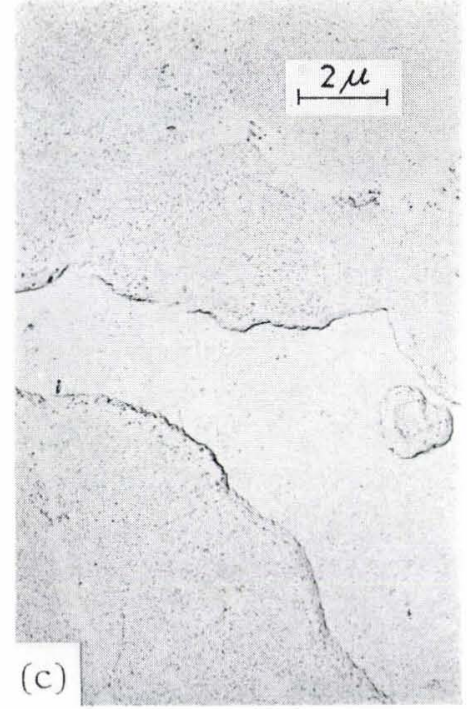

(a): coiled at $750^{\circ} \mathrm{C}$ (transmission)

(b): coiled at $600^{\circ} \mathrm{C}$ (transmission)

(c): coiled at $600^{\circ} \mathrm{C}$ (extraction replica)

(d): diffraction pattern obtained from (c)

Photo. 1. Electron micrographs of $0.005 \% \mathrm{C}-0.096 \% \mathrm{Ti}$ steel after hot rolling with different coiling temperatures

the $\mathrm{C}$ and $\mathrm{N}$ in the steel were fixed as $\mathrm{TaC}(\mathrm{N})$ by the precipitation treatment of the hot-rolled sheet, but left unclarified the size effect of fine precipitates.

Mould, et al. ${ }^{21)}$ investigated the relationships between $\mathrm{Nb}$ carbonitride in the hot-rolled sheet and the texture and $r$ value of the cold-rolled annealed sheet using an Nb-containing low Mn low C steel. They simulated in the laboratory the coiling conditions after hot rolling to change the state of precipitation and obtained $\mathrm{Nb}$ carbonitride of 40 to $500 \AA$ precipitated upon high temperature coiling at $1450^{\circ} \mathrm{F}\left(788^{\circ} \mathrm{C}\right)$ and Nb carbonitride of 10 to $160 \AA$ upon low temperature coiling at $1100^{\circ} \mathrm{F}\left(593^{\circ} \mathrm{C}\right)$. Accordingly, the $\bar{r}$ value of the cold-rolled annealed sheet which at the hotrolled stage was coiled at the higher temperature was significantly higher than that of the other coiled at the lower temperature after being hot-rolled (the $\bar{r}$ value of the former was 2.09 against 1.3 of the latter in the case of $0.087 \% \mathrm{Nb}$ steel). Mould, et al. also examined the effect of changes in the size of precipitates made by altering $\mathrm{Nb}$ content and the conditions of precipitation, and found that the $r$ value of the sheet subsequently cold-rolled and annealed was particularly low when the diameter of the precipitate particles was in the order of $10 \mu$ and that when the precipitates included those in the order of $1000 \mu$ and, in addition, the amount of $\mathrm{Nb}$ in solid solution was high, the $r$ value was not satisfactorily high. They concluded that precipitates ( $\mathrm{Nb}$ carbonitrides) within the size range of 40 to $500 \AA$ (or 0.04 to $0.5 \mu$ in interparticle spacing) would be effective in promoting textures of high plastic anisotropy desirable for deep drawing and also in providing preferred texture selection during the nucleation and/or growth stage of recrystallization process.

The authors studied the effect of precipitates prior 
to cold rolling using a Cu-containing steel $(0.05 \% \mathrm{C}-$ $0.60 \% \mathrm{Cu}$ ) besides the Ti-stabilized steel. ${ }^{22)}$ In the test, a hot-rolled sheet of Cu-containing steel was treated at $650^{\circ} \mathrm{C}$ for approximately $10 \mathrm{hr}$ to let $\varepsilon-\mathrm{Cu}$ precipitate. By this treatment the $r$ value of the coldrolled annealed sheet was remarkably improved, and the particle size of $\varepsilon-\mathrm{Cu}$ precipitated in the hot-rolled sheet was approximately $200 \AA$.

With all these results seen in perspective, it will be clear that if the second phase of precipitates in the order of $100 \AA$ exists in a hot-rolled sheet prior to cold rolling, the recrystallization texture conductive to raising the $r$ value of the cold-rolled annealed sheet can be developed. Therefore, the precipitation control of conventional Al-killed steel of deep drawing quality, i.e., retaining $\mathrm{Al}$ and $\mathrm{N}$ in supersaturated solid solution before cold rolling and slowly heating the steel for annealing so as to get AlN precipitates just before recrystallization, is not the only method available for developing $\{111\}$ recrystallization texture. Although there may be, as stated before, some difference in the role played in recrystallization texture formation by the prior precipitates (precipitated in hot-rolled sheet) and by the later precipitates (precipitated during heating for annealing after cold rolling), at least it has been proved by this study on Ti-stabilized steel, by the results of Furubayashi, et al., and by those of Toda, et al., that if very fine precipitates exist in hotrolled sheets, slow heating for annealing after cold rolling so as to promote precipitation of effective precipitates required to develop the textures of high $r$ value is unnecessary and therefore a rapid heating cycle such as of a continuous annealing process is applicable.

Among the test results of Al-killed steel shown previously (in Fig. 3), the $\bar{r}$ value of the sample coiled at a high temperature of $750^{\circ} \mathrm{C}$ was generally low with a large range of deviation which can be considered as being due to the excessively large particle size of AIN precipitates. It can also be assumed that an inordinately high coiling temperature promotes the growth of ferrite grain, thus increasing $\{110\}$ constituent, reducing $\{111\}$, and lowering the $\bar{r}$ value. ${ }^{23)}$ No experiment, however, was conducted to ascertain the validity of this assumption.

\section{Crystal Grain Size and the $r$ Value}

As is clear from Fig. 4, the $r$ value becomes larger with the increase in the grain size. Because of differences in the ease of grain growth among various types of steels, however, such steels with retarded grain growth as Al-killed steel and V-containing rimmed steel have a certain limit to the rise of the $r$ value. On the other hand, when the rimmed steel is decarburization-annealed, its grain growth is facilitated. It therefore becomes possible by utilizing the above phenomenon to obtain an $r$ value for rimmed steel equal to that of Al-killed steel of deep drawing quality. Ti-stabilized very low $\mathrm{C}$ steel is also provided with ease of grain growth. The rise of its $r$ value is remarkable. The $\bar{r}$ value rises to as high as 2.8 against 6.5 as a commercial limit of grain size number. This has never been realized so far by other conventional types of steel. No reason has been ascertained, however, for discontinuity of relationship between the $\bar{r}$ and the grain size in the finer grain size range in Fig. 4.

Karlyn, et al. ${ }^{17)}$ worked out the following empirical formula for the relation between the $\bar{r}$ value and the grain size number $(\mathrm{N})$.

$$
\bar{r}=\bar{r}_{0}-K\left(\mathcal{N}_{\circ}-\mathcal{N}\right)
$$

The constant $K$ does not vary much among different steel types and stays around 0.35. $\mathrm{N}_{\circ}$ being the number for the grain size immediately after recrystallization, the $\bar{r}$ value of an annealed steel for which no attempt has been made to promote grain growth is expressed as $\bar{r}_{\circ}$ in the above formula. Namely, $\bar{r}_{\circ}$ represents the basic state of a deep drawing quality steel, and therefore is the term which is influenced most by steel type, additives, hot rolling, cold rolling, and other manufacturing conditions. The order of the $r$ values of different types of steel at the same grain size level in Fig. 4 can be considered proportionate to the value of $\bar{r}_{\circ}$. It is clear that the $\bar{r}_{\circ}$ of Ti-stabilized steel is the largest of all the steels in the figure. The second term of the above formula reflects the rise of the $r$ value due to grain growth. Therefore, if grain growth of Ti-stabilized steel is promoted, the $r$ value of the steel is further improved from its already high basic $r$ value, or $\bar{r}_{\text {。 value. }}$

The grain growth of Ti-stabilized steel is influenced primarily by the $\mathrm{C}$ content of the steel. ${ }^{16)}$ An example of the test results is shown for reference in Fig. 5, (where values of $\mathrm{C}$ and $\mathrm{Ti}$ contents indicate melt targets and no check analysis of them was conducted). The steel having the lowest content of $\mathrm{C}(0.02 \% \mathrm{C})$ in

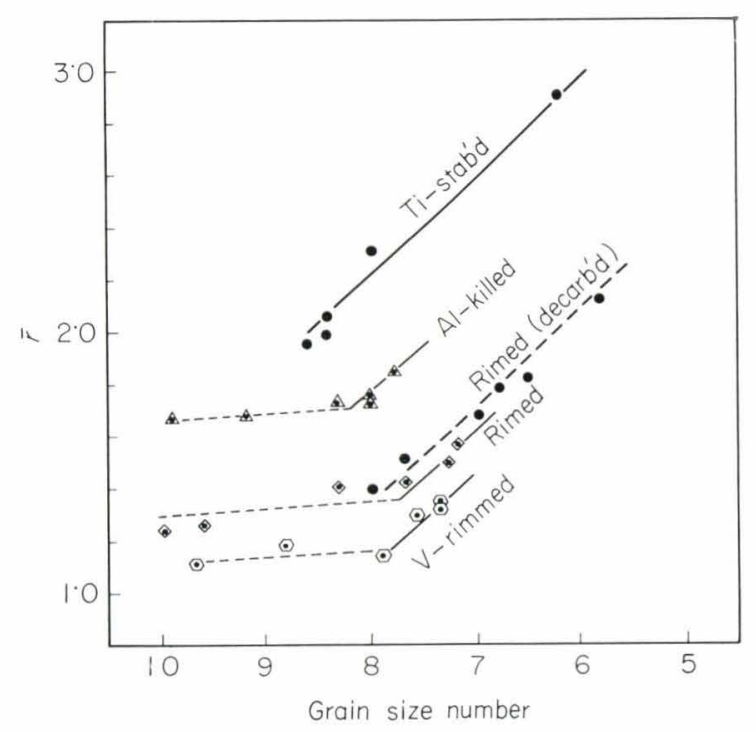

Normal annealing: soaked 6 hr in dry HNX gas at temperatures

Decarburization annealing: soaked $5 \mathrm{hr}$ in wet hydrogen gas of $30^{\circ} \mathrm{C}$ D.P. and dried $1 \mathrm{hr}$ at temperatures

Fig. 4. Relation between the $r$ value and grain size for various steels cold-rolled $70 \%$ and annealed. Grain size was varied by controlling annealing temperature 
the figure showed a remarkable improvement in the $r$ value with the rise of annealing temperature. It is therefore effective in generating satisfactory grain growth in a short cycle such as of continuous annealing, to reduce the $\mathrm{C}$ amount of the steel and raise the annealing temperature. As can be expected from the test results of the decarburized rimmed steel in Fig. 4, the grain growth of simple very low C (nonTi-stabilized) steel sheet processed from decarburized molten steel can also be promoted by a short annealing cycle and consequently a comparatively high $r$ value is obtained for the sheet steel.

The results of the experiment conducted on the basis of the above findings to determine the optimum annealing condition for Ti-stabilized very low $\mathrm{C}$ steel are shown in Fig. 6. As shown in the figure, the annealing temperature, if the allowable grain size number is set at 6.5 , can be raised to $930^{\circ} \mathrm{C}$ for a holding time of $1 \mathrm{~min}$ and to $910^{\circ} \mathrm{C}$ for a holding time of $5 \mathrm{~min}$, and in the case of $10 \mathrm{~min}$ any temperature in the temperature range adopted for the experiment produced coarse grains whose grain size number is approximately 6 or less. Because $\alpha \rightleftarrows \gamma$ transformation occurs in steel, though dependent on the duration of holding time, at about $940^{\circ} \mathrm{C}$ or higher, the highest temperature to which the steel is to be heated should be $930^{\circ} \mathrm{C}$ (of course, this critical temperature is also influenced by the heating rate adopted).

A field test was conducted to ascertain the applicability of the above laboratory test results to the production line. The results of the test are shown in Fig. 7, where it is clear that the crystal grains of continuously annealed steels except that annealed at $930^{\circ} \mathrm{C}$ for $3.9 \mathrm{~min}$ grow to an appropriate size producing mechanical properties superior to those of batch-annealed steels (in the $r$ value and Erichsen value). The steel annealed at $930^{\circ} \mathrm{C}$ for $3.9 \mathrm{~min}$ underwent the $\alpha \rightleftarrows \gamma$ transformation and its texture was that of random orientation. Because the heating rate was slightly slower on the production line than in the laboratory furnace, the $\mathrm{A}_{\mathrm{C}_{3}}$ point may have lowered from that in the laboratory furnace. Photograph 2 shows the microstructure of a steel batch-annealed at $780^{\circ} \mathrm{C}$ for $1 \mathrm{hr}$ (left) and that of a steel annealed continuously at $930^{\circ} \mathrm{C}$ for $1.1 \mathrm{~min}$ (right) (the sample

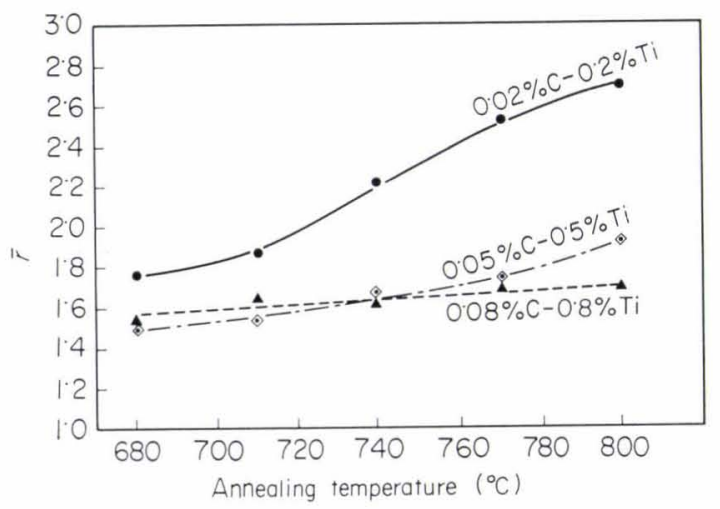

Fig. 5. Effect of annealing temperature on the $r$ value of Tistabilized steel with different $\mathrm{C}$ contents, cold-rolled $70 \%$ and annealed $5 \mathrm{hr}$ at temperatures which was batch-annealed was not included in the steels shown in Fig. 7, but was taken separately from a production mill). It has now become clear that, if the grain growth of Ti-stabilized steel is promoted through a high-temperature continuous annealing process, superior mechanical properties, i.e., the extradeep drawability (very high $r$ value) and the good

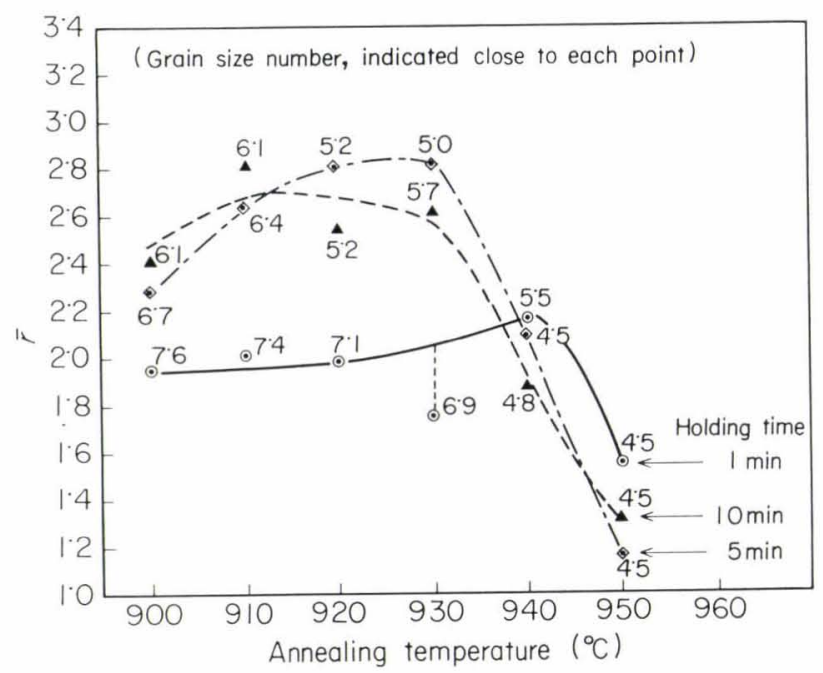

Fig. 6. Effect of annealing condition (high temperature and short holding time) on the $r$ value of Ti-stabilized very low $\mathrm{C}$ steel, finished at $910^{\circ} \mathrm{C}$, coiled at $570^{\circ} \mathrm{C}$, cold-rolled $70 \%$, and annealed

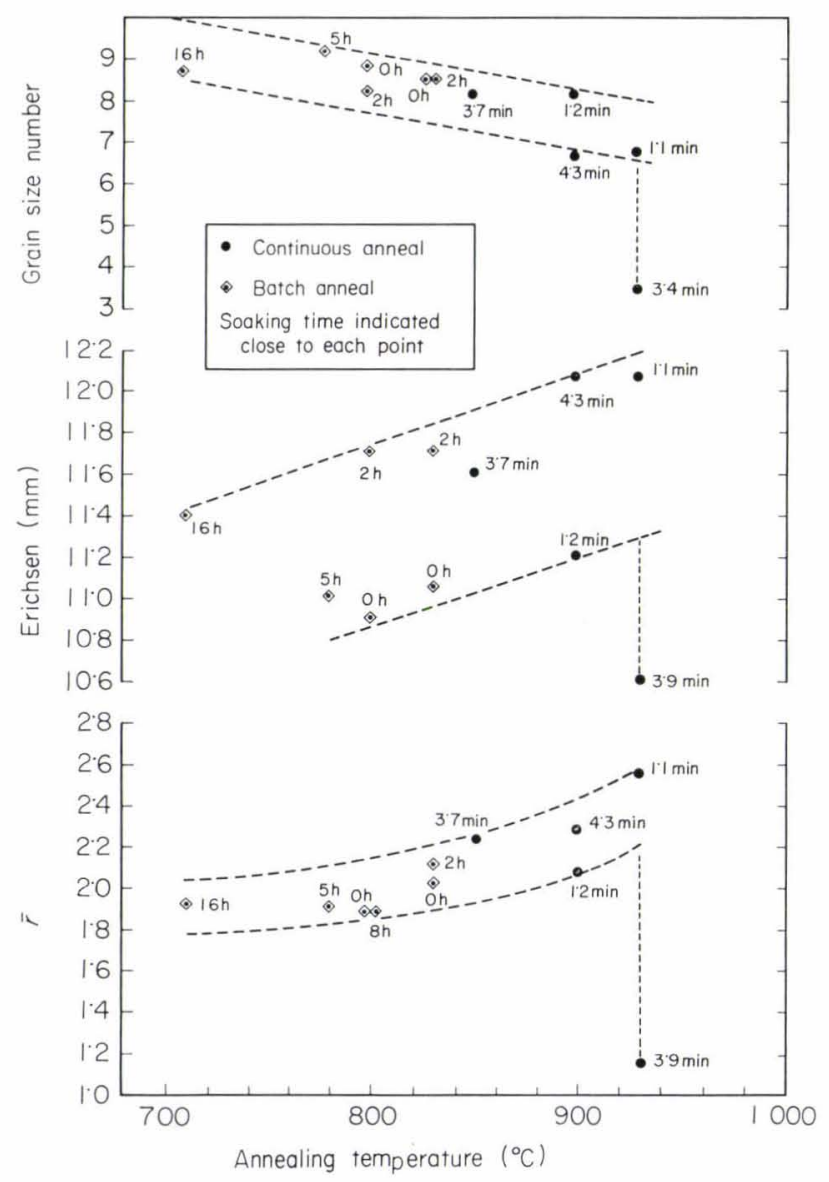

Fig. 7. Effect of annealing practice on the $r$ value, Erichsen value and grain size of Ti-stabilized steel shown in Table 3 

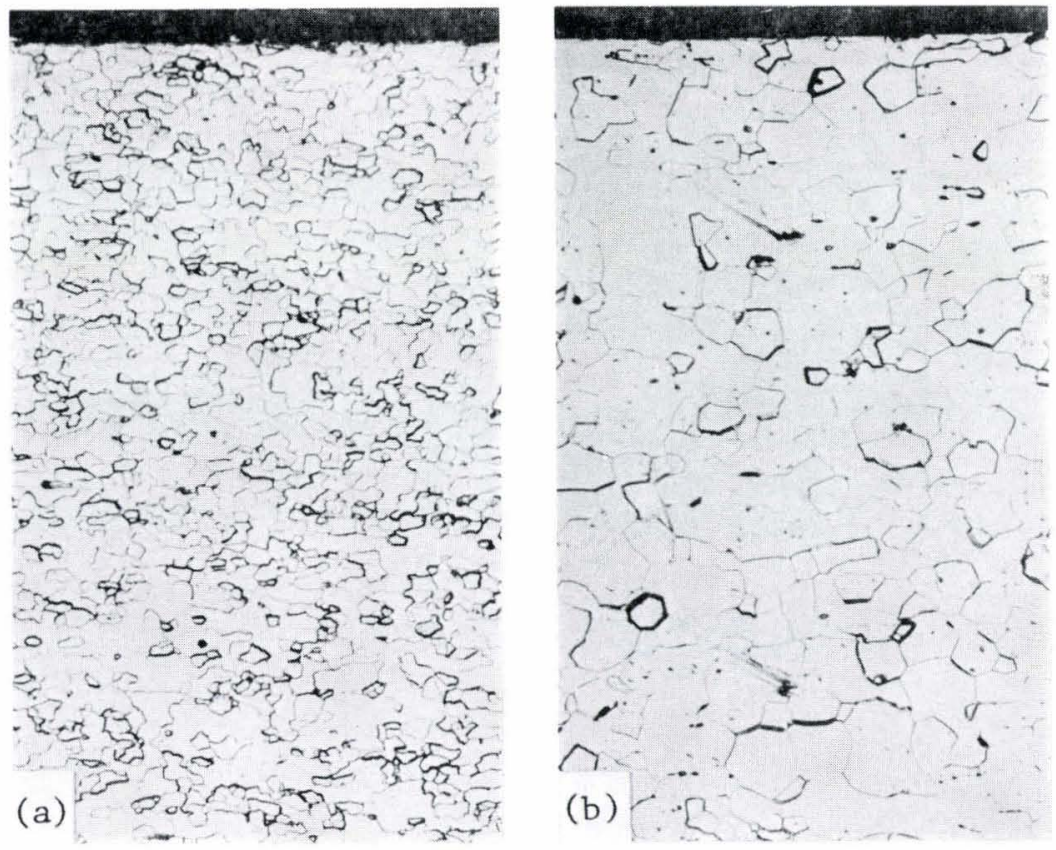

(a): batch-annealed at $780^{\circ} \mathrm{C}$ for 1 hr (G.S. No. 8.7)

(b): continuous-annealed at $930^{\circ} \mathrm{C}$ for $1.1 \mathrm{~min}$ (G.S. No. 6.7)

Photo. 2. Microstructures

after batch-annealing and continuousannealing, respectively, of very low $\mathrm{C}$ Ti-stabilized steel cold-rolled $70 \%$ $(\times 100)$

stretchability (Erichsen value) which have never been obtained by any conventional method can now be provided to the steel. In many cases, however, such a superior formability may not be needed in commercial press operations. Hence, in the application of a continuous annealing cycle, the temperature to which the strip is heated can be lowered, or the strip threading speed can be increased according to the required mechanical properties. For uses requiring surface quality more than press formability, a lowtemperature continuous annealing process should be applied in order to obtain a fine grain structure. Further, if cold reduction is increased from normal 60 $70 \%$ to $80 \sim 90 \%$, a very high $r$ value is obtainable while keeping a comparatively fine grain structure even if high temperature continuous annealing is applied. Changes in the $\bar{r}$ value and grain size with the annealing condition are shown in Fig. 8 as a function of cold reduction.

\section{Effect of Overaging}

In a batch type furnace, the as-coiled material is furnace-cooled from the annealing temperature, and therefore is not subject to quench hardening since the $\mathrm{C}$ in the steel precipitates as carbide. Among continuously annealed steels, overaging is of necessity for soft products such as deep drawing quality sheets, while unnecessary for high temper tin plate, etc., which require a degree of hardness. Because the lower the overaging temperature, the longer the required time, the suitable overaging conditions for the production line will be determined considering steel properties, productivity, equipment cost, etc., in overall perspective. Time required for softening steels was studied using 3 types of steel and an overaging temperature of $400^{\circ} \mathrm{C}$. The test results, given in Fig. 9, show that both rimmed steel and Al-killed steel soften by overaging treatment for 1 to $5 \mathrm{~min}$ (with low yield point and high elongation value), but beyond this time range mechanical properties are not so improved. In contrast, however, Ti-stabilized steel does not require any overaging treatment at all while maintaining a low yield point and a high elongation. Moreover, the steel does not show any rise in yield point even when artificially aged at $100^{\circ} \mathrm{C}$ for $1 \mathrm{hr}$, thus proving that it is nonaging.

The chemical composition of the Ti-stabilized steel of extra-deep drawing quality is adjusted to approximately $\mathrm{C} \leq 0.01 \%$ and $\mathrm{Ti} / \mathrm{C} \geq 10,{ }^{5)}$ and that which is shown in Table 1 can be regarded as a typical one. $\mathrm{N}$ in the steel of such chemical composition precipitates as TiN at the stage of molten steel or in the course of solidification. ${ }^{18)}$ Mori, et al. ${ }^{19)}$ worked out $\log [\% \mathrm{Ti}][\% \mathrm{C}]=-10300 / \mathrm{T}+5.12$ as a temperature function of the equilibrium density product of $\mathrm{Ti}$ and $\mathrm{C}$ in austenite, showing that almost all $\mathrm{C}$ in the steel is stabilized by $\mathrm{Ti}$. Therefore, in the annealing process after cold rolling, the steel does not show any quench age-hardening even when quenched from the annealing temperature, since solid solutioning of C hardly occurs though heated to about $950^{\circ} \mathrm{C}$.

\section{Conclusions}

(1) Ti-stabilized steel, already in the hot-rolled state, has very fine precipitates, TiC, effective in developing $\{111\}$ recrystallization texture, requires no slow heating for annealing after cold rolling, and allows rapid heating while maintaining a very high $r$ value.

(2) Ti-stabilized very low $\mathrm{C}$ steel promotes grain growth with the rise of annealing temperature, shows a remarkable improvement in the $r$ value resulting from the preferential grain growth of $\{111\}$, and affords an extremely high $r$ value through very short time annealing.

(3) Because $\mathrm{C}$ in the steel is stabilized by $\mathrm{Ti}$, Tistabilized very low $\mathrm{C}$ steel does not require any overaging treatment to prevent quench age-hardening even 

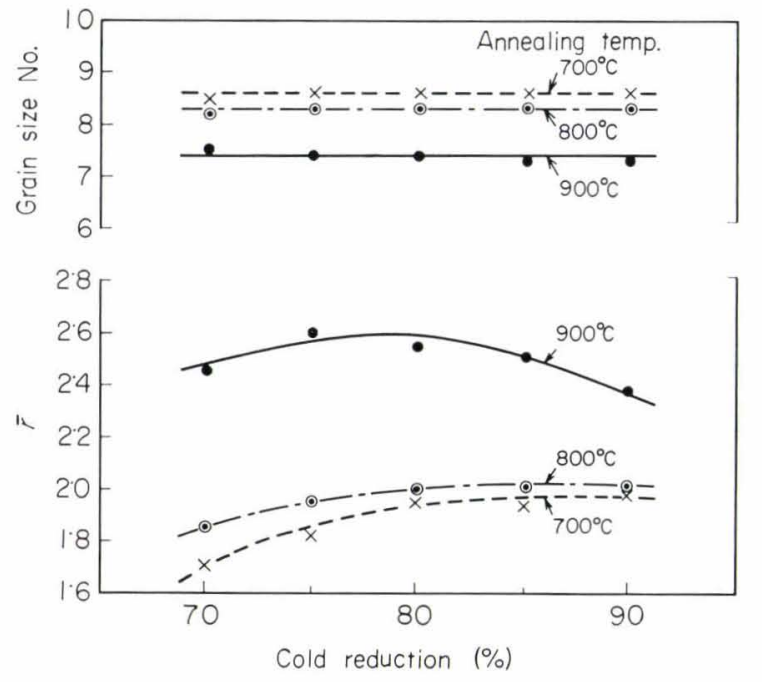

Fig. 8. Effect of prior cold reduction on the $r$ value and grain size of Ti-stabilized very low $\mathrm{C}$ steel finished at $930^{\circ} \mathrm{C}$, coiled at $550^{\circ} \mathrm{C}$, and annealed $2 \mathrm{~min}$ at indicated temperatures after cold rolling $(0.005 \% \mathrm{C}$ $0.030 \% \mathrm{Si}-0.10 \% \mathrm{Mn}-0.009 \% \mathrm{P}-0.013 \% \mathrm{~S}-0.118 \%$ Ti- $-0.0065 \% \mathrm{~N}$ )

when quenched from the annealing temperature, and provides a soft and non-aging material.

(4) The adoption of Ti-stabilized very low C steel has solved all the problems of properties arising from the application of a short annealing cycle inclusive of rapid heating and quenching, thus making it possible to produce with ease cold-rolled sheets having superior press-formability characterized by extra-deep drawability and good stretchability through a continuous annealing line of commercial scale.

\section{REFERENCES}

1) N. Takahashi: Preprint for the 57th Meeting of Japan Inst. Metals, (1965), 51.

2) M. Shimizu, K. Matsukura, N. Takahashi and Y. Shinagawa: Tetsu-to-Hagané, 50 (1964), 2097.

3) D. J. Blickwede: Flat Rolled Products, ed. by T. E. Dancy and E. L. Robinson, Interscience Publishers, New York, (1959), 91.

4) S. Garber: JISI, 200 (1962), 466.

5) N. Fukuda and M. Shimizu: J. Japan Soc. for Technology of Plasticity, 13 (1972), 841.

6) N. Takahashi, M. Shimizu, S. Nagata and H. Takechi: Preprint for the 67th Meeting of Japan Inst. Metals, (1970), 86.

7) N. Takahashi, H. Takechi and M. Shimizu: Preprint for the 69th Meeting of Japan Inst. Metals, (1971), 104.

8) J. Bennewitz: Arch. Eisenhüttenw., 33 (1962), 393.

9) J. T. Michalak and R. D. Shoone: Trans. AIME, 242 (1968), 1149.

10) H. Abe and K. Takagi: Tetsu-to-Hagané, 55 (1969), 1219.

11) M. Matsuo and S. Hayami: Preprint for the 66th Meeting of Japan Inst. Metals, (1970), 180.

12) H. Takechi: Preprint for the 19th Joint Meeting of Kyushu Branch, JIM \& ISIJ, (1968), 10.

13) T. Shiraiwa, F. Terasaki and T. Kodama: Preprint for
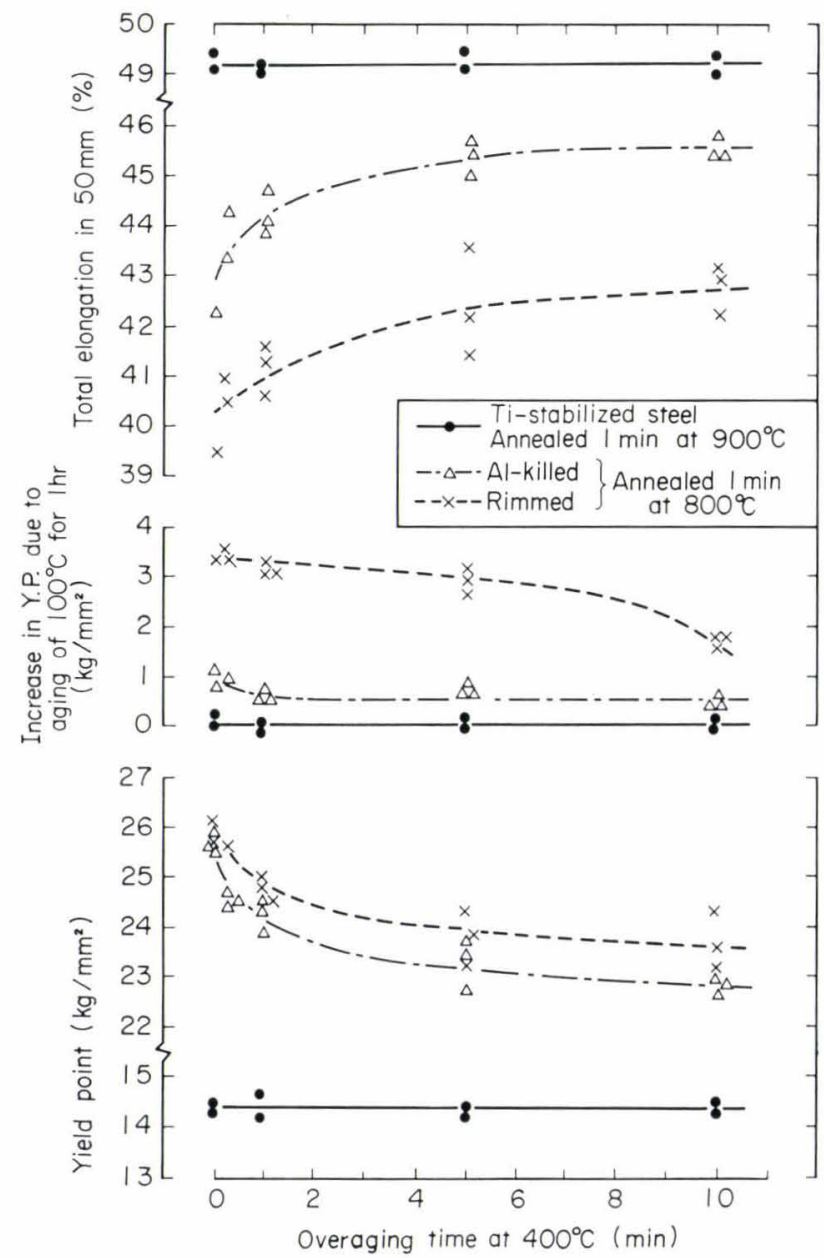

Fig. 9. Effect of overaging treatment on the mechanical properties and strain aging of steels cold-rolled, continuously annealed and skin-passed $1 \%$. Samples overaged for indicated time at $400^{\circ} \mathrm{C}$ on the way of cooling from annealing temperature.

the 62nd Meeting of Japan Inst. Metals, (1968), 188.

14) E. Furubayashi and H. Endo: Tetsu-to-Hagané, 58 (1972), S471.

15) K. Toda, M. Nishiwaki, H. Gondo, H. Takechi and M. Abe: Tetsu-to-Hagané, 59 (1973), S497.

16) N. Fukuda, M. Shimizu and N. Takahashi: Report of the 7th Meeting of Recrystallization Committee, ISIJ, No. Tetsu Sai-46, July, (1973).

17) D. A. Karlyn, R. W. Vieth and J. L. Forand: Mechanical Working and Steel Processing VII, ed. by G. A. McGrann, D. W. Murphy and F. E. Richardson, AIME, (1969), 127.

18) H. Sawamura and T. Mori: Tetsu-to-Hagané, 43 (1957), 31

19) T. Mori, M. Tokizane and T. Karasudani: Tetsu-to-Hagané, 50 (1964), 2004.

20) I. Kokubo, M. Sudo, K. Kameno, S. Hashimoto, I. Tsukatani and T. Iwai: Tetsu-to-Hagané, 59 (1973), 469.

21) P. R. Mould and J. M. Gray: Met. Trans., 3 (1971), 3121.

22) M. Shimizu, N. Takahashi and K. Suemune: Tetsu-toHagané, 58 (1972), S267.

23) M. Matsuo, S. Hayami and S. Nagashima: Advances in X-ray Analysis, XIV, Plenum Press, (1971), 214. 